\title{
Louis Dubeau: putting aside biases and validating accustomed dogmas make successful scientists
}

Submitted Jul 09, 2018. Accepted for publication Jul 12, 2018.

doi: $10.21037 /$ tcr.2018.07.12

View this article at: http://dx.doi.org/10.21037/tcr.2018.07.12

\section{Editor's note}

"Every scientist develops biases throughout his/her career," said Prof. Louis Dubeau, Professor of Pathology and Medical Director of Molecular Pathology, USC Norris Comprehensive Cancer Center, University of Southern California, USA, in an interview with Translational Cancer Research (Figure 1), "We ought to put aside such biases when analyzing scientific data, revise our working bypothesis, and revisit even widely accepted dogmas when they no longer account for scientific observations."

Always is it easier said than done, yet Prof. Dubeau, who has been putting sustained efforts into the study of the biology and molecular genetics of ovarian cancer, used action to speak for himself-cancers traditionally referred to as ovarian carcinomas were commonly believed to be derived from the coelomic epithelium. Instead of sticking to this accustomed dogma, Prof. Dubeau refuted and superseded it years ago with his own hypothesis that it is the extra-uterine tissues embryologically derived from the Müllerian ducts that actually play a role in ovarian embryogenesis, and put forth the term "serous extra-uterine Müllerian carcinomas" to describe this type of tumors $(1,2)$.

In this interview, Prof. Dubeau is going to share with us the hypothesis that he put forward, the significance of studying this carcinoma at a molecular level, the study that he is recently involved in, and some interesting behind-thescene stories in his research and clinical work.

\section{Expert introduction}

Louis Dubeau, $\mathrm{MD}, \mathrm{PhD}$, currently serves as the Professor of Pathology and Medical Director of Molecular Pathology, USC Norris Comprehensive Cancer Center, Keck School of Medicine, University of Southern California, USA. He is a world-renowned expert, leading practitioner, researcher and educator in the field of ovarian cancer biology studying into the biology, pathology and molecular genetics of ovarian cancer, mechanisms of aneuploidy during cancer development, detection and identification of cancer cells through molecular genetic testing, tumor cell division and enzyme telomerase,

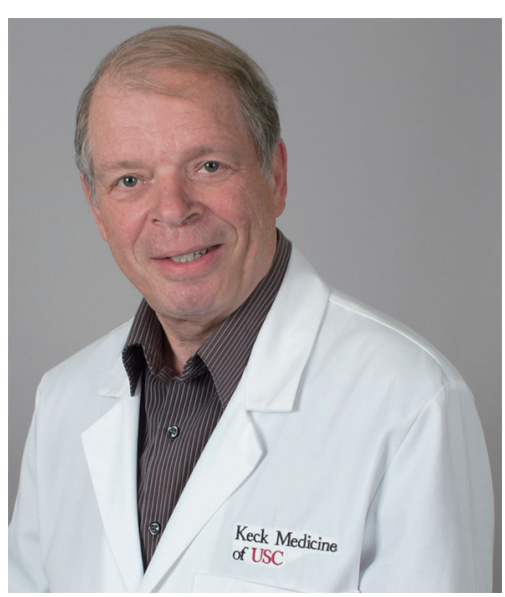

Figure 1 Prof. Louis Dubeau.

tissue dissection and microdissection and so forth.

Prof. Dubeau entered USC as a post-doctoral fellow at the Norris Comprehensive Cancer Center, where he soon became the full professor and director of the Molecular Diagnostics Laboratory. He is actively involved in academic activities such as publishing peer-reviewed articles in various medical journals, including Translational Cancer Research, giving lectures at international conferences and seminars across the US, England and Europe, and mentoring MD and $\mathrm{PhD}$ students as well as giving lectures to public school students on health-related subjects.

\section{Interview}

TCR: Why is it important to study the development and progression of serous extra-uterine Müllerian carcinomas at a molecular level?

Prof. Dubeau: I am glad that you use the term "extrauterine Müllerian carcinomas" to designate tumors traditionally referred to as ovarian carcinomas because this term more accurately reflects their true tissue of origin, which is usually located outside the ovary.

Understanding the molecular mechanism of development 
of any cancer type is essential to develop an effective strategy for their prevention and for the detection of their precursor lesions. In the context of serous extra-uterine Müllerian carcinomas, we know that menstrual cycle activity is an important risk factor, including in individuals with genetic predisposition such as a germline BRCA1 mutation, but we do not know why. Elucidating the underlying mechanism could not only facilitate the development of strategies to prevent these tumors, but also should facilitate the development of biomarkers for molecular events associated with their precursor lesions, allowing screening of populations with an elevated cancer risk.

\section{TCR: How will the understanding about the cell-non- autonomous mechanisms of cancer predisposition assist clinical work?}

Prof. Dubeau: Cell-non-autonomous mechanisms of cancer predisposition in individuals with $B R C A 1$ mutations refer to mechanisms whereby cancer predisposition is not driven by direct consequences of such mutations in cells in which cancer risk is elevated, but in cells whose functions influence the latter from a distance. For example, ovarian follicles play a central role in controlling the menstrual cycle, which in turn is an important risk factor for extra-uterine Müllerian carcinomas. Consequences of BRCA1 mutations on the biology of ovarian follicles could therefore influence cancer risk indirectly in extra-uterine Müllerian tissues through alterations in the menstrual cycle. There is no physical contact between ovarian follicles and such tissues, implying that such influence would be mediated exclusively by secreted factors, such as sex steroid hormones. Imbalances in factors present in the circulation are much easier to detect and repair than abnormalities in intra-cellular metabolic pathways confined to cells with an increased cancer risk, underscoring the potential impact of understanding cell-non-autonomous effects.

TCR: You have hypothesized that ovarian carcinomas arise from tissues that are embryologically derived from the Müllerian ducts instead of the ovarian coelomic epithelium. Can you explain the hypothesis?

Prof. Dubeau: Tissues that are derived from the Müllerian ducts have morphological characteristics that are readily distinguishable from those of the coelomic epithelium. Cancers traditionally referred to as ovarian carcinomas have characteristics that closely mimic those of tissues derived from the Müllerian ducts, hence the hypothesis that these tumors originate in such tissues. Some of the reasoning that led pathologists of the early twentieth century to hypothesize that ovarian carcinomas were derived from the coelomic epithelium is no longer valid. For example, it used to be thought that the coelomic epithelium, also called germinal epithelium, was the origin of many of the cells present within the ovary including germ cells. The idea that this epithelium was the site of origin of ovarian cancer seemed attractive in light of such alleged potential to differentiate into multiple specialized cell types. However, it is now known that the coelomic epithelium does not have such roles in ovarian embryogenesis. It is also clear that cancers traditionally referred to as ovarian carcinomas do not always originate in the ovary. This led to the hypothesis that extra-uterine tissues that are embryologically derived from the Müllerian ducts are the site of origin of those tumors. Such tissues, which are most abundant on the fimbrial ends of fallopian tubes but can also be found in the para-tubal and para-ovarian regions and even within the ovaries, can differentiate toward all major cell lineages corresponding to the various histological subtypes of these tumors such as serous, endometrioid, etc. This hypothesis can account for the current scientific data to my knowledge. It can also readily explain the anatomic location of ovarian cystadenomas, the benign counterparts of the carcinomas, which are common outside the ovaries.

\section{TCR: What is the correlation between air pollution and the morbidity and mortality of extra-uterine Müllerian cancer?}

Prof. Dubeau: I do participate in ongoing environmental studies at my institution, largely through my position in a service core laboratory where molecular biological analyses linked to these studies are performed. However, this is not done in the context of extra-uterine Müllerian cancer. Some environmental factors such as direct exposure to talc may influence the development of high-grade serous extrauterine Müllerian carcinomas. Smoking may predispose to the mucinous subtype of these tumors. However, highgrade serous extra-uterine Müllerian carcinomas are primarily hormone-driven and not driven significantly by air pollution, unless dealing with pollutants that have consequences on the menstrual cycle.

\section{TCR: Would you introduce us to a recent NIH study that you are involved in?}

Prof. Dubeau: I am currently seeking funding from NIH for a study focused on using mouse models looking at consequences of the BRCA1 mutation carrier state in extra-uterine Müllerian epithelia and in ovarian follicles independently of each other in order to fully understand 
the relative contributions of cell-autonomous and cellnon-autonomous mechanisms of cancer predisposition in $B R C A 1$ mutation carriers. If successful, these studies should not only have a significant impact on cancer prevention in such carriers, but also provide useful surrogate biomarkers of success in cancer prevention trials.

\section{TCR: Would you share with us a most memorable clinical case you came across?}

Prof. Dubeau: I came across a case where a tumor in the adnexal area showed multiple different lineages including serous, endometrioid, and mucinous. This tumor clearly involved the fimbrial epithelium as well as soft tissues surrounding the fallopian tube but spared the ovary. In other words, it showed features of 3 common subtypes of what we then called ovarian carcinoma but did not involve the ovary. This case, which I encountered early in my career, contributed to my questioning of the merit of the dogma that these tumors originate from the ovarian surface.

\section{TCR: What do you regard as the most difficult and interesting aspects of being a scientist?}

Prof. Dubeau: Every scientist develops biases throughout his/her career. One of the most difficult aspects of science is to put aside such biases when analyzing scientific data, whether from your own laboratory or from that of others, and revise your working hypothesis, no matter how attractive it seems, if it is not fully supported by the data.

To have an opportunity to see first-hand how your own scientific contributions can impact patient care and to contribute to the formation and education of trainees by sharing your own experiences are the most interesting and rewarding aspects of being a physician scientist working in a large academic institution.

\section{TCR: As a professor of pathology, what would be your} advice to students who would like to become successful in the field?

Prof. Dubeau: Hypotheses are formulated to account for what is known at a specific period in time in order to provide a framework for future research. This is how scientific progress is made. Some hypotheses, such as the idea that ovarian carcinomas originate in coelomic epithelium, so readily account for current scientific observations at the time that they are formulated that they become widely accepted dogmas. My advice to young investigators and students is to keep an open mind and do not hesitate to revisit the merit of such dogmas when they no longer account for scientific observations.

\section{Acknowledgments}

We would like to express our sincerest gratitude to Prof. Louis Dubeau for sharing his insights and opinions with us. Funding: None.

\section{Footnote}

Provenance and Peer Review: This article was commissioned by the Editorial Office, Translational Cancer Research. The article did not undergo external peer review.

Conflicts of Interest: The author has completed the ICMJE uniform disclosure form (available at http://dx.doi. org/10.21037/tcr.2018.07.12). The author has no conflicts of interest to declare.

Ethical Statement: The author is accountable for all aspects of the work in ensuring that questions related to the accuracy or integrity of any part of the work are appropriately investigated and resolved.

Open Access Statement: This is an Open Access article distributed in accordance with the Creative Commons Attribution-NonCommercial-NoDerivs 4.0 International License (CC BY-NC-ND 4.0), which permits the noncommercial replication and distribution of the article with the strict proviso that no changes or edits are made and the original work is properly cited (including links to both the formal publication through the relevant DOI and the license). See: https://creativecommons.org/licenses/by-nc-nd/4.0/.

\section{References}

1. Dubeau L. The cell of origin of ovarian epithelial tumors and the ovarian surface epithelium dogma: does the emperor have no clothes? Gynecol Oncol 1999;72:437-42.

2. Dubeau L. The cell of origin of ovarian epithelial tumours. Lancet Oncol 2008;9:1191-7.

(Science Editor: Brad Li, TCR, tcr@amepc.org)

Cite this article as: Li B. Louis Dubeau: putting aside biases and validating accustomed dogmas make successful scientists. Transl Cancer Res 2018;7(Suppl 7):S816-S818. doi: 10.21037/ tcr.2018.07.12 